\title{
Central nervous system regeneration: the roles of glial cells in the potential molecular mechanism underlying remyelination
}

\author{
Lili Quan, Akiko Uyeda and Rieko Muramatsu* (D)
}

\begin{abstract}
Glial cells play crucial roles in brain homeostasis and pathogenesis of central nervous system (CNS) injuries and diseases. However, the roles of these cells and the molecular mechanisms toward regeneration in the CNS have not been fully understood, especially the capacity of them toward demyelinating diseases. Therefore, there are still very limited therapeutic strategies to restore the function of adult CNS in diseases such as multiple sclerosis (MS).

Remyelination, a spontaneous regeneration process in the CNS, requires the involvement of multiple cellular and extracellular components. Promoting remyelination by therapeutic interventions is a promising novel approach to restore the CNS function. Herein, we review the role of glial cells in CNS diseases and injuries. Particularly, we discuss the roles of glia and their functional interactions and regulatory mechanisms in remyelination, as well as the current therapeutic strategies for MS.
\end{abstract}

Keywords: Central nervous system, Glial cell, Remyelination, Systemic factors, Multiple sclerosis

\section{Introduction}

Adult central nervous system (CNS) has a limited regenerative capacity following injury or disease. Glial cells (astrocytes, oligodendrocytes, and microglia) are the major glial populations of the CNS and are crucial for brain development and homeostasis as well as the pathological process (Fig. 1). Remyelination is a regenerative process in the CNS, which occurs spontaneously and counters demyelinating diseases to restore lost neurological deficits and axonal function [1, 2]. Successful remyelination depends on the involvement of multiple cell types around the lesion site, and glial cells are one of the most important cell groups in this process [3]. With aging, diminished activity of progenitor cells such as oligodendrocyte precursor cells (OPCs) within the nervous system means that reversal of the damage caused by CNS diseases and injuries becomes

\footnotetext{
* Correspondence: muramatsu@ncnp.go.jp

Department of Molecular Pharmacology, National Institute of Neuroscience, National Center of Neurology and Psychiatry, 4-1-1 Ogawa-higashi, Kodaira, Tokyo 187-8502, Japan
}

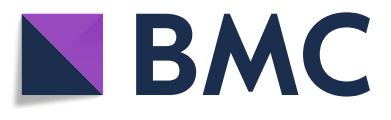

(c) The Author(s). 2022 Open Access This article is licensed under a Creative Commons Attribution 4.0 International License, which permits use, sharing, adaptation, distribution and reproduction in any medium or format, as long as you give

appropriate credit to the original author(s) and the source, provide a link to the Creative Commons licence, and indicate if changes were made. The images or other third party material in this article are included in the article's Creative Commons licence, unless indicated otherwise in a credit line to the material. If material is not included in the article's Creative Commons licence and your intended use is not permitted by statutory regulation or exceeds the permitted use, you will need to obtain permission directly from the copyright holder. To view a copy of this licence, visit http://creativecommons.org/licenses/by/4.0/. increasingly impossible [2]. Currently, there are no effective therapies in regard to treating the demyelinating diseases. Thus, illustrating the underlying molecular mechanism of remyelination is beneficial to the development of therapeutic strategies for CNS injuries and diseases. In this review, we discussed the properties of glia and their functions in CNS remyelination. Notably, we emphasized the role of systemic factors regulating the processes of OPCs in remyelination and glia-glia interaction in this process, providing a novel direction to combat the challenges of demyelination caused by injury, diseases, and aging of the brain. Furthermore, we summarized the therapeutic strategies that are currently being used in demyelinating disease-multiple sclerosis (MS), paving the way for the development of therapeutics for CNS remyelination.

\section{Main text \\ Oligodendrocyte progenitor cell and oligodendrocyte Oligodendrocyte progenitor cells, also known as oligo- dendrocyte precursor cells (OPCs), which express}



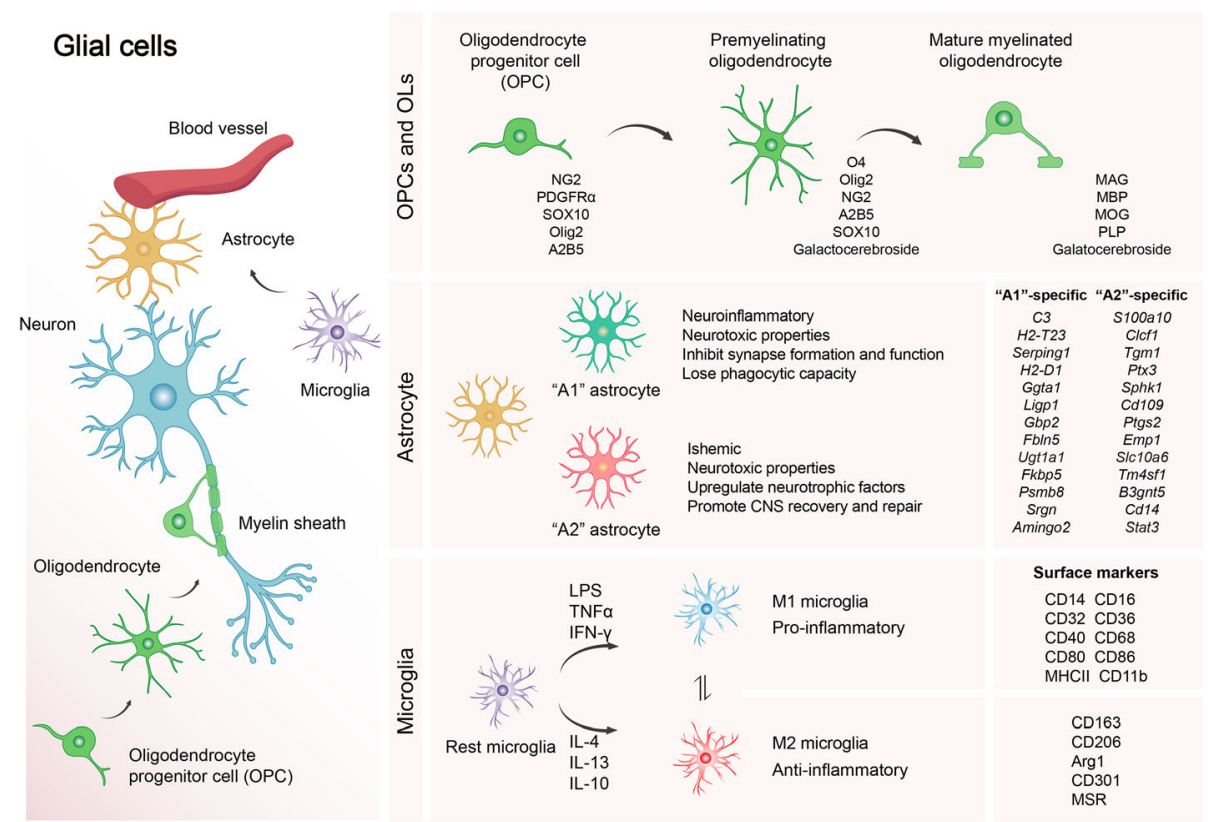

Fig. 1 Schematic representation of glial cells in the CNS, along with their classification and representative marker genes. Oligodendrocytes, astrocytes, and microglia are the major population of glial cells in CNS. Oligodendrocytes (OLs) are myelinating cells derived from oligodendrocyte progenitor cells (OPCs). OLs and OPCs are important cellular components for remyelination, which is an important regenerative process to restore lost neurological function. OPCs express PDGFRa (platelet-derived growth factor receptor a), the transcription factor SOX10, NG2, Olig2, and A2B5. After OPCs generate OLs, the cells start to express O4, galactocerebroside. Finally, mature myelinating OLs express myelinassociated glycoprotein (MAG), myelin basic protein (MBP), proteolipid protein (PLP), and myelin oligodendrocyte glycoprotein (MOG). Astrocytes are the most abundant cells in the mammalian CNS with the function of forming and maintaining blood-brain barrier (BBB), regulating regional blood flow, proving trophic, antioxidant and metabolic support to neurons, neurotransmitter recycling, immune signaling, and regulating neuronal synaptogenesis and synaptic transmission. Reactive astrocytes can be classified into two subtypes, termed as "A1" (neurotoxic)/ "A2" (neuroprotective) astrocytes, with the specific marker genes identified from the previous transcriptome analysis [49]. Microglia can be classified into two states: M1 (classic) or M2 (alternative), which are responsible for tissue injury and repair, respectively

proteoglycan neuron-glial antigen 2 (NG2), are the main dynamic, proliferative cells within the adult CNS [4]. Mature oligodendrocytes (OLs) are differentiated from OPCs during the embryogenesis and early stages of postnatal life [5]. Moreover, in adult, there is still an undifferentiated population of OPCs maintained in the CNS, which hold the capacity to continue into mature OLs through activation, proliferation, migration, and differentiation for the adaptive myelin sheath formation [6]. Multiple transcriptional factors and growth factors play essential roles in oligodendrocyte differentiation and maturation [7-15]. For example, in response to a demyelinating insult, OPCs are recruited to the demyelination areas and activated by the upregulation of transcription factors, such as Olig1, Olig2, Nkx2.2 [7], Sox10 [10], and Sox2 [11]. Subsequently, OPCs proliferate under the modulation of growth factors such as fibroblast growth factor (FGF) and platelet derived growth factor (PDGF) from the CNS microenvironment [3], and finally differentiate into mature OLs to form the myelin sheaths that wrap the exposed demyelinated axons under the regulation of factors including myelin regulatory factor (Myrf) [12], TCF7L2 [13, 14], and
Sox17 [15]. According to the protein expression pattern of the development of oligodendrocyte, multiple markers have been developed to recognize the cell at different stages [16] (Fig. 1). However, the potential of OPCs for differentiation is different between brain regions and age, which is correlated with electrophysiological changes and molecular or cellular environments [17-19].

The progression of OPCs is increasingly implicated in neurodegenerative diseases such as MS, as OLs not only myelinate, but also provide metabolic support for axons [20]. Traditionally, OPCs, rather than pre-existing mature oligodendrocytes, have been identified as the cells most responsible for remyelination [21]. Surprisingly, recent evidences suggest that adult oligodendrocyte also can participate in remyelination [16]. Through the light and electron microscopy, they found that oligodendrocytes are connected to remyelinated and mature myelin sheaths. In vitamin $\mathrm{B}_{12}$-deficienct nonhuman primates demyelination model, it shows that survived mature oligodendrocyte is capable to extend and connect demyelinated axons, demonstrating that partially injured mature oligodendrocytes also hold the ability to participate in myelin repair of demyelinating diseases [22]. 
More recently, study using single-nucleus RNA sequencing revealed seven clusters of OLs and additional OPCs clusters with specific or enriched RNA markers for each subclusters in the white matter of MS patient brain, suggesting the heterogeneity of oligodendrocyte may relate to different functional states of oligodendrocytes in MS progression [20]. Additionally, Yeung, M.S.Y [23] uncovers oligodendrocyte generation dynamics in MS using carbon-dated strategy to measure the ${ }^{14} \mathrm{C}$ level in genomic DNA of oligodendrocytes from different stages. Enrichment-based approaches of MS genome-wide association studies SNPs nominate the oligodendrocyte intrinsic contribution in MS pathogenesis via the disruption of RNA polymerase II release [24]. Together, those results indicate that OLs and OPCs are key players in MS. Beyond MS, dysfunction of oligodendrocyte is also found in schizophrenia and bipolar disorder [25]. OPCs senescence induced by $\beta$-amyloid plays a role in neuroinflammation and cognitive deficits in Alzheimer's disease $(\mathrm{AD})[26]$.

\section{Regulation of systemic factors of remyelination}

From the previous published results using the in vitro oligodendrocytes culture or in vivo zebrafish and mouse model, showing that multiple extrinsic factors, as well as systemic factors are responsible for remyelination. Some of those factors or receptors have been regarded as potential targets for the development of drugs to treat demyelinating-related diseases, such as MS [27]. Currently, illustration of the pathophysiological function of circulating factors from vascular disruption has been emerged to be novel strategies toward remyelination for CNS regeneration (Fig. 2). Based on the previous studies, we described that multiple circulating factors released from the bio-system exhibit essential roles in OPC development, for example the fibrinogen [28], fibroblast growth factor 21 (FGF21) [29], transforming growth factor- $\beta 1$ (TGF- $\beta 1$ ) [30], and apelin [31].

Fibrinogen Fibrinogen is a blood coagulation protein synthesized in liver [32]. Upon blood-brain barrier (BBB) disruption, fibrinogen leaks into the brain, and, by

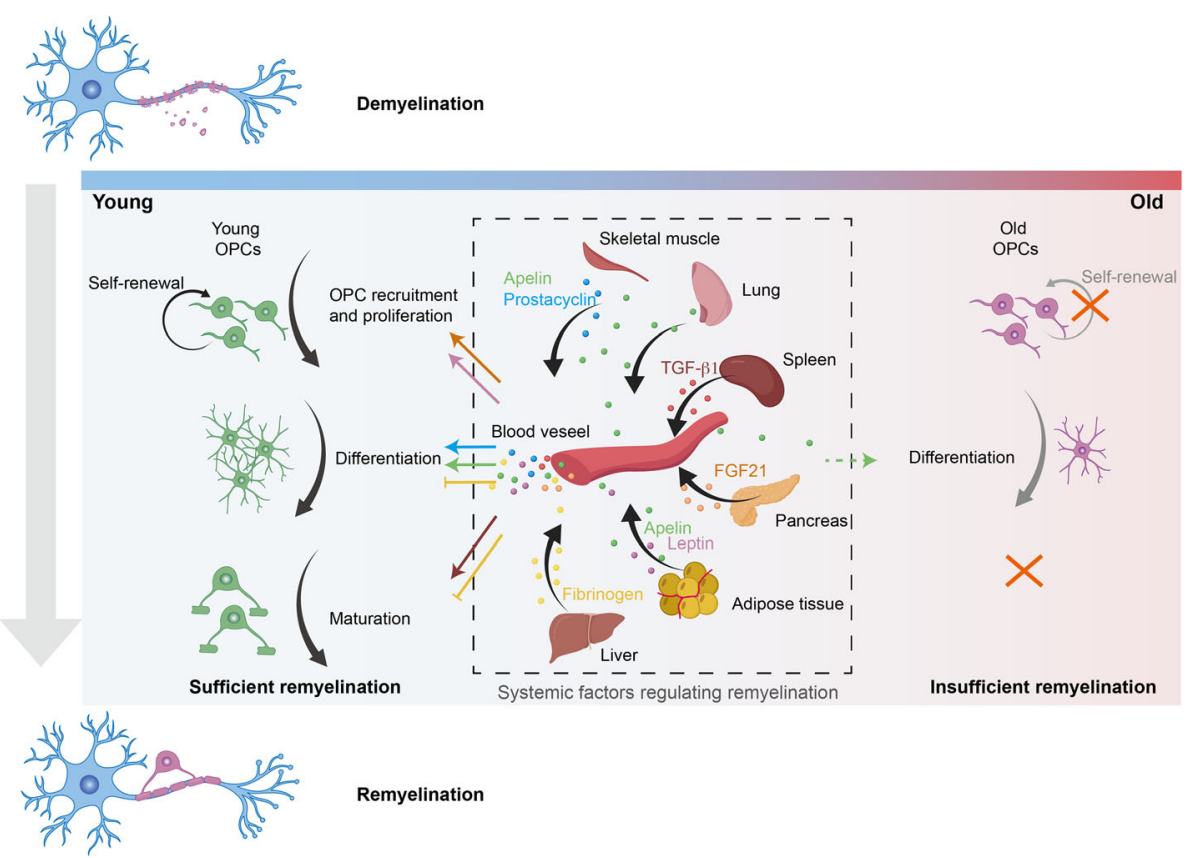

Fig. 2 Molecular mechanism of remyelination in CNS. In response to the CNS injury to myelinate axons, remyelination is initiated with oligodendrocyte progenitor cells (OPCs) recruitment and activation to the lesion site. Then followed by OPCs proliferation, differentiation, and maturation to mature oligodendrocyte for myelin sheath formation. CNS injuries often along with the disruption of blood-brain barrier (BBB) in the lesion site. Systemic factors leaked from BBB contribute to the remyelination through promoting OPCs proliferation, differentiation, and maturation. Pancreas-derived FGF21 and adipose tissue-derived leptin promotes OPCs proliferation; skeletal muscle-derived prostacyclin, and lung, muscle, adipose tissue-derived apelin are responsible for the oligodendrocyte differentiation; spleen-derived transforming growth factor- $\beta 1$ in serum induces the oligodendrocyte maturation. In contrast, fibrinogen disrupts OPCs differentiation and myelination upon BBB disruption. Therapeutic depletion of fibrinogen will be benefit for remyelination. OPCs, similar to other adult stem cell, undergo a functional decline with ageing. The ability of OPCs to self-renew and to differentiate is diminished. Also, the efficiency of oligodendrocyte differentiation is declined with age. In particular, the expression of apelin receptor (APJ) in oligodendrocytes is decreased and result in an insufficient remyelination. Alternatively, activation of APJ promotes the remyelination both in aged mice and toxin-induced EAE. Therefore, activation of apelin/APJ signaling restores the function of oligodendrocyte for differentiation and thereby enhance its capacity for remyelination 
activation of the bone morphogenetic protein (BMP) pathway to inhibit oligodendrocyte differentiation and remyelination. Exposing OPCs to fibrinogen in vitro, the differentiation of OPCs into OLs is inhibited as shown by the decreased MBP expression. Through the OPC/ dorsal root ganglion myelinating and fibrinogen-coated nanofiber myelinating culture system, they found that fibrinogen significantly suppresses the $\mathrm{MBP}^{+} \mathrm{OLs}$ and myelin sheath formation, suggesting that fibrinogen inhibits the oligodendrocyte maturation. In order to understand the mechanism about how fibrinogen affects OPC differentiation, the authors used whole-genome microarray and gene ontology analysis and found that BMP responsive genes (Id1, Id2, Nog, Hes1, Hey1, and Lef1) were upregulated upon fibrinogen treatment of OPCs. With the treatment of BMP type I receptor ACVR1 inhibitor, DMH1 or CRISPR/Cas9 ACVR1 knockout, the inhibitory effect of fibrinogen on OPCs was significantly blocked, suggesting that fibrinogen activates the BMP signaling via ACVR1 to show its inhibitory effect on OPCs differentiation and myelin production. Depletion of fibrinogen in lysophosphatidylcholine (LPC)-induced demyelination mouse model, the BMP signaling is inhibited and the remyelination is enhanced [28]. Thus, fibrinogen is a potential therapeutic target for promoting the remyelination and repair of demyelinating-related diseases. Interestingly, they found that OPCs exposed to fibrinogen underwent a development of astrocytes both in vitro and in vivo. Accumulating evidence suggests that blood-derived fibrinogen triggers astrocyte scar formation [33] and is involved in neural stem cell differentiation into astrocyte within the subventricular zone niche following the brain injury [34]. It is possible that the blood leakage factors may perform different but cooperative functions in multiple cellular types to achieve its function for CNS regeneration.

FGF21 FGF21, which is predominantly expressed in pancreas, mediates OPC proliferation by interaction with $\beta$-klotho which is an important coreceptor of FGF21 [31]. In vivo, when injection of LPC to the spinal cord to construct the demyelination with vascular barrier disruption, the FGF21 concentration was also increased as the same time course of OPC proliferation in the injury lesion. Knockout of FGF21 showed a decreased spontaneous remyelination and functional recovery following LPC injection. When silencing the expression of FGF21 in pancreas, the serum-mediated OPC proliferation was significantly inhibited, indicating the critical role of pancreas-derived FGF21 in OPCs proliferation and CNS remyelination [29].

TGF- $\beta 1$ TGF- $\beta 1$, which shows appreciable expression in the spleen, promotes oligodendrocyte maturation for the achievement of remyelination and functional recovery of myelin oligodendrocyte glycoprotein (MOG) ${ }_{35-55}$ induced EAE model. With the treatment of adult mouse serum, the oligodendrocyte maturation is promoted dramatically via TGF- $\beta$ type I receptor, as assessed via the determination of the MBP-positive area. Similarly, the enhancement of oligodendrocyte maturation induced by TGF- $\beta 1$ was also observed in human samples assessed by the mRNA level of myelin-associated proteins, MBP, MAG, and PLP, using quantitative RT-PCR in vitro. Administration of TGF- $\beta 1$ to demyelinating animal models promotes the remyelination and functional recovery. These results suggest that circulating factors from the disruption of vascular barrier play critical roles in demyelinating-diseases [30].

Apelin Apelin/APJ improves oligodendrocyte differentiation during ageing and age-related pathologies to promote remyelination. By comparing the RNA expression profile data from developing and aged mice focusing on the genes associated with the differentiation markers, Aplnr appears to be a potential biomarker of oligodendrocyte differentiation and responsible for the promotion of rejuvenation of aged-related dysfunction of remyelination. The expression of APJ in myelin-forming cells decreases with age, and is correlated with a decrease in myelinassociated genes. The expression of Apln is detected in multiple tissues, including the lung, adipose tissue, and skeletal muscle, all of which also exhibit reduced Apln expression in aged animals. APJ agonist ML233 treatment in aged mice with LPC-induced demyelination resulted in the recovery of neurological function and promotion of remyelination compared to that in the control mice. In addition, the oligodendrocyte maturation was also confirmed by upregulated-expression of myelin-associated proteins (Mbp, Plp, and Mog) in human OPC with the stimulation of ML233. Thus, it is promising that the dysfunction of apelin/APJ signaling is associated with the failure of ageing-related demyelination, indicating a novel critical role of circulating factors in age-related CNS remyelination [31].

Other factors Besides the above discussed circulating factors, endocrine hormones secreted from muscle cells promote OPCs proliferation and myelination [35]; heartderived factors hold the ability to promote OPCs proliferation through the phosphorylation of phosphatidylinositol 3-kinase and extracellular signalregulated kinase [36]; the adipose tissue abundant leptin is also responsible for the promotion of OPC proliferation in toxin-induced demyelination model and in vitro [37]. Taken together, it is no doubt that systemic factors are essential mediators of brain homeostasis, ageing, and neurodegeneration [38], in particular, circulating factors and its corresponding receptors are potential targets for 
remyelination and for the development of drugs for CNS diseases.

\section{Astrocyte}

Astrocytes, the most abundant glial cells, play a critical role in both physiology and pathology processes of CNS. It is becoming clear that astrocytes hold a wide range of functions: associating with endothelial cells, neurons, and pericytes to form and maintain $\mathrm{BBB}$; regulating regional blood flow; proving trophic, antioxidant and metabolic support to neurons, neurotransmitter recycling, immune signaling; and regulating neuronal synaptogenesis and synaptic transmission [39-45]. In response to CNS injury, astrocytes will turn into reactive astrocytes with a notable feature of the upregulation of glial fibrillary acidic protein (GFAP) at both of the mRNA and protein levels. Thus, GFAP has been widely regarded as a marker for reactive astrocytes. However, only focusing on GFAP and morphology are not sufficient to evaluate astrocytes as reactive, because the degree of GFAP expression in reactive astrocytes is modulated due to the regional difference, the proximity to the injury site, and the type or severity of injuries [46]. Therefore, combination of molecular markers (GFAP with other astrocyte markers such as aldehydedehydrogenase-1 L1, S100B, glutamine synthetase, aldolase-C) and functional readouts is recommended to evaluate the astrocyte phenotypes [47].

Reactive astrocytes can classified into two subtypes; "A1" (neurotoxic) and "A2" (neuroprotective) astrocytes, based on transcriptomic and epigenetic studies that profiled reactive astrocytes from lipopolysaccharide-induced neuroinflammation or middle cerebral artery occlusioninduced ischemic stroke mouse model separately [48] (Fig. 1) . Compared to normal astrocytic functions, "A1" astrocytes lose their phagocytic capacity and their capacity to clear myelin debris in vivo after CNS injury [49]. Thus, the inhibition of "A1" astrocyte formation after acute CNS injury is presumed to prevent the death of axotomized neurons [50]. Whereas, "A2" astrocytes upregulate multiple neurotrophic factors and play a protective role in promoting CNS recovery and repair [49]. However, the binary classification of reactive astrocytes (A1/A2) has been challenged by single-cell and singlenucleus RNA-seq analyses, and spatial transcriptomics in the tissue samples from various CNS diseases such as AD [51], Huntington's disease [52, 53], and amyotrophic lateral sclerosis [54]. Thus, the previously profiled marker genes classified as either "A1/neurotoxic" or "A2/neuroprotective" is speculative and needs to be further investigated, and more comprehensive single-cell genomic analyses and representative models are needed to accelerate our understanding of astrocyte subtypespecific profiles. Ongoing single-cell genomic studies, spatial transcriptomics, and conditional knockdown or knockout experimental models $[55,56]$ have enabled the investigation of the morphology and physiology of different distributions of astrocyte populations under normal or pathological conditions. Thus, in the future, it may be possible to distinguish astrocyte subtypes in a more comprehensive manner.

\section{Roles of astrocytes in remyelination}

The details of the function of astrocytes in remyelination toward OPCs or other cell types such as Schwann cells have been widely discussed elsewhere [57]. In brief, reactive astrocytes were induced by activated microgliasecreted cytokines (interleukin-1 $\alpha$ [IL-1 $\alpha]$, tumor necrosis factor [TNF], and C1q) in response to demyelinating insults. Astrocytes exhibit a dual function during remyelination by secreting either regenerative or inhibitory factors, which modulate the proliferation, differentiation, and maturation of OPCs (Fig. 3). Astrocytes promote OPC proliferation through growth factors plateletderived growth factor AA (PDGF-AA), FGF2, cytokines interleukin-1 $\beta$ (IL-1 $\beta$ ), TNF, and chemokine C-X-C motif chemokine ligand 1,8 , and 10 (CXCL1, CXCL8, CXCL10) [58-62]. Astrocytes also promote OPC differentiation by secreting ciliary neurotrophic factor (CNTF) [63], leukemia inhibitory factor (LIF) [64], insulin-like growth factor-1 (IGF-1) [65], and tissue inhibitor of metalloproteinases-1 (TIMP-1) [66]. Moreover, astrocytes produce inhibitory molecules, such as chondroitin sulfate proteoglycans (CSPGs) [67], endothelin-1 (ET-1) [68], fibronectin [69], tenascin-c [70], and jagged-1 [71] which have an inhibitory role in remyelination, as well as brain-derived neurotrophic factor (BDNF), hyaluronan, and fibroblast growth factor 9 (FGF9), to facilitate or suppress the maturation of OLs [72-74] (Fig.3). In addition to the secretion of regulatory factors to regulate remyelination as described above, astrocytes also play a role in mediating copper transport [75] and recruiting microglia into demyelinating lesions to promote their phagocytic function [76]. Recent evidence suggests that astrocytemediated copper transport promotes demyelination and tissue injury [75]. This study further finds that astrocytedependent copper is distributed in the white matter of human and mouse models of MS. It is possible that reducing the distribution of copper may sufficiently promote remyelination and tissue repair [75]. Furthermore, astrocytes may also support remyelination by controlling cholesterol synthesis and transfer via apolipoprotein E $[77,78]$.

\section{Microglia}

Microglia can be defined as both glia and resident macrophage-like immune cells of CNS, which play a critical role in CNS development, homeostasis, and in response of brain injury. In the physiological conditions, 


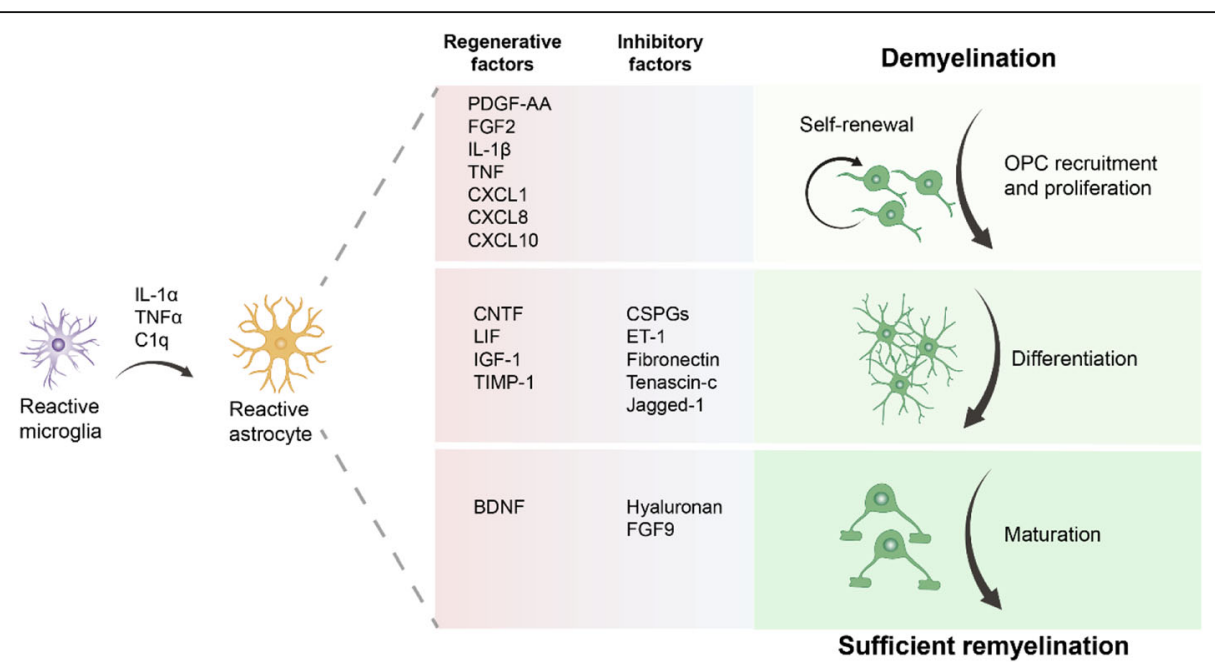

Fig. 3 Roles of astrocytes in remyelination. Reactive astrocytes are induced by cytokines (interleukin [IL]-1a, TNF, and C1q) secreted by activated microglia in response to demyelinating insults. Astrocytes regulate the proliferation, differentiation, and maturation of OPCs by secreting regenerative or inhibitory factors that modulate remyelination. Astrocytes promote OPC proliferation by producing growth factors such as platelet-derived growth factor AA (PDGF-AA), fibroblast growth factor 2 (FGF2), cytokines IL-1 $\beta$ and tumor necrosis factor (TNF), and chemokine C-X-C motif chemokine ligand 1, 8, and 10 (CXCL1, CXCL8, CXCL10). Astrocytes increase OPC differentiation by secreting ciliary neurotrophic factor (CNTF), leukemia inhibitory factor (LIF), insulin-like growth factor-1 (IGF-1), and tissue inhibitor of metalloproteinases-1 (TIMP-1). In contrast, astrocytes also produce inhibitory molecules, such as chondroitin sulfate proteoglycans (CSPGs), endothelin-1 (ET-1), fibronectin, tenascin-C, and jagged-1. Furthermore, astrocytes produce brain-derived neurotrophic factor (BDNF) to promote hyaluronan and fibroblast growth factor 9 (FGF9) to suppress the maturation of OLs

microglia interact with the surrounding neurons, astrocytes, and oligodendrocytes to show its homeostatic function through cell-to-cell communication and synapse formation [79]. In the pathological conditions, microglia have the capacity to change the morphology rapidly and response to the stimuli adoptively in numerous CNS disorders. In response to acute CNS injury, the activation of microglial is induced in both mammals and zebrafish [80]. Growing evidence indicates that microglial necroptosis and repopulation drive CNS remyelination [81]. Traditionally, microglia can be classified into two states: M1 (classic) and M2 (alternative) state (Fig. 1). M1 is a pro-inflammatory state with the upregulation of MHC class II and the release of pro-inflammatory cytokines, IL-1 $\beta$, IL-6, IL15, TNF- $\alpha$, and IFN- $\gamma$. M2 is an anti-inflammatory state with the production of trophic factors, like tumor growth factor- $\beta$ (TGF- $\beta$ ), IL-10, growth factor IGF-1, and BDNF [82]. In the classical conversion of microglia to M1 microglia, the NF- $\mathrm{kB}$ and iNOS pathways are upregulated to defend the tissue and facilitate the destruction of invading pathogens in response to injury and infection. However, M1 microglia also induce neurotoxicity by producing multiple proinflammatory cytokines and inducing acute inflammation. The activation of M1 microglia induces the expression of iNOS, and the depletion of iNOS expression sufficiently protects $\mathrm{AD}$ mice from cerebral plaque formation and premature mortality, and increases the $\mathrm{AD}$ protective response [83]. After classical activation, anti- inflammatory and repair processes are rapidly initiated with the activation of the M2 microglia, which have the potential to suppress pro-inflammatory immune responses and promote damage repair [84]. Recent studies have shown that transplantation of M2-deviated microglia rather than M1 microglia efficiently accelerates the motor function recovery in SCI mouse models [85]. Moreover, M2-derived activin-A drives the differentiation of oligodendrocytes, indicating that M2 cell polarization is crucial for successful remyelination [86].

\section{Roles of the microglia in remyelination}

Microglia promote remyelination by facilitating the proliferation and differentiation of OPCs in three manners: (1) phagocytosis of myelin debris, (2) secretion of regenerative factors, and (3) regulation of the extracellular matrix [87] (Fig. 4). The phagocytosis of myelin debris is regulated by the CX3CR1 and $\mathrm{RXR}-\gamma$ receptors expressed in the microglia [88, 89]. CX3CR1 knockout mice exhibit diminished myelin debris clearance after cuprizone-induced demyelination [88]. RXR- $\gamma$, whose expression decreases with age, coincides with impaired debris clearance after demyelination [89]. The phagocytosis of myelin debris can be reduced by antagonism or knockout [90]. Recent studies have further highlighted the role of microglia in myelin debris phagocytosis. The depletion of microglia following treatment with PLX5622 (an inhibitor of colony stimulating factor 1 receptor, CSF1R) in mice in the later stage of delayed viral 


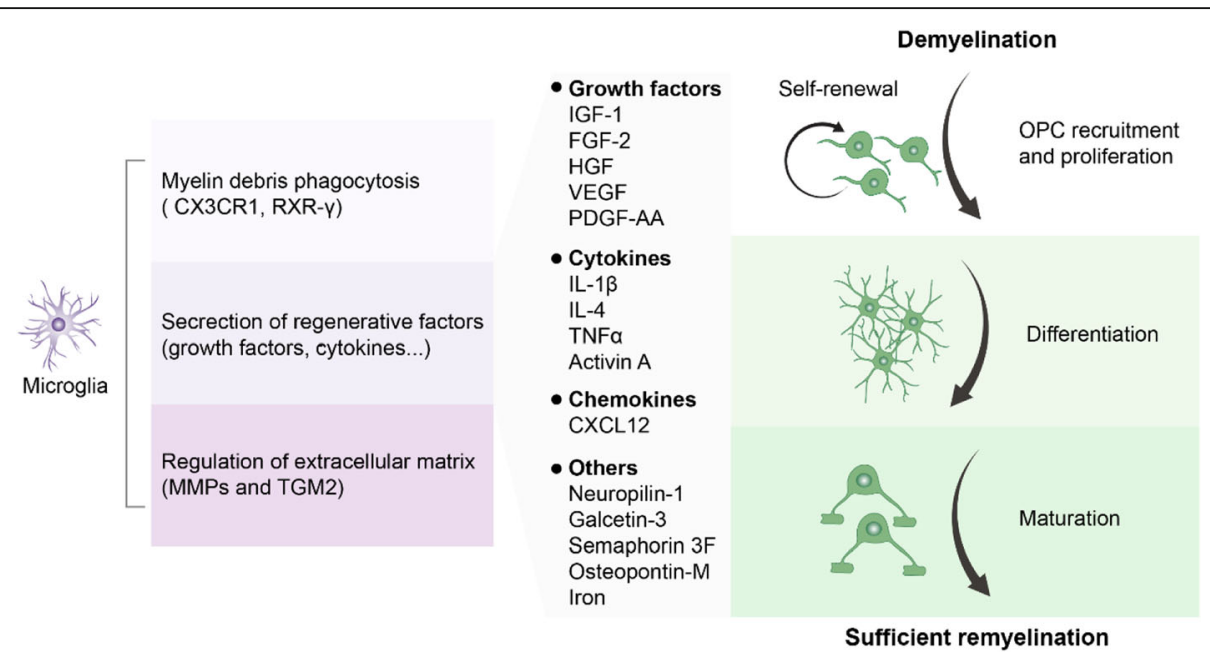

Fig. 4 Roles of microglia in remyelination. Microglia promote remyelination to facilitate OPC proliferation and differentiation for myelin formation by the following three mechanisms: (1) myelin debris phagocytosis (via CX3CR1 and RXR- $\gamma$ receptors). (2) Secretion of regenerative factors such as growth factors, insulin-like growth factor 1 (IGF-1), fibroblast growth factor-2 (FGF-2), hepatocyte growth factor (HGF), vascular endothelial growth factor (VEGF), platelet-derived growth factor AA (PDGF-AA); cytokines, interleukins-1 $\beta$ and 4 (IL-1 $\beta$, IL-4), tumor necrosis factor a (TNFa), activin A; chemokine, C-X-C motif chemokine ligand 12 (CXCL12); and others, including neuropilin-1, galectin-3, semaphorin 3F, osteopontin-M, and iron. (3) Modulation of the extracellular matrix by secretion of matrix metalloproteinases (MMPs) and TGM2

clearance induced by coronavirus infection, microgliadepleted mice fail to recover clinically from hindlimb paralysis, or to resolve demyelinating lesions [91]. Microglia also regulate OPC proliferation and OL differentiation by secreting various pro-regenerative factors, including growth factors, insulin-like growth factor 1 (IGF1), FGF2, hepatocyte growth-factor (HGF), vascular endothelial growth factor (VEGF), PDGF-AA; cytokines, IL-1 $\beta$, IL-4, TNF, and activin A (a member of the TGF- $\beta$ superfamily); chemokine, $\mathrm{C}-\mathrm{X}-\mathrm{C}$ motif chemokine ligand 12 (CXCL12), and others including neuropilin-1, galectin-3, semaphorin 3F, osteopontin-M, and iron [90]. Additionally, the function of IL-4 in microglia has been shown to enhance oligodendrogenesis in EAE mice and promote oligodendrocyte differentiation during remyelination [92]. Recent studies have also revealed the mechanism underlying the transition of pro-inflammatory to pro-regenerative microglia during remyelination [81] (Fig. 4). RNA sequencing using isolated microglia from myelin toxin LPCinduced focal demyelinated lesions in the corpus callosum of young adult mice illustrated that microglial repopulation is positively regulated by type-1 IFN signaling during white matter remyelination, suggesting that targeting inflammatory microglia is a potential strategy for CNS white matter inflammation [81].

\section{MS}

MS, a widely occurring demyelinating disease of the $\mathrm{CNS}$, is characterized by continuous inflammation, demyelination, and axonal loss [93]. In clinical practice, immunotherapies have been widely developed for the treatment of MS, including ocrelizumab, an anti-CD20 monoclonal antibody, which was approved in 2017 by the Food and Drug Administration for the treatment of primary progressive MS [94]. However, the precaution of disability in MS patients from axonal and neuronal injury and loss has not been achieved due to incomplete or inadequate remyelination and is therapeutically challenging in clinical settings [95]. Therefore, promoting remyelination may have significant implications for improving disability in patients with MS.

Currently, multiple in vivo models have been developed to screen for potential therapeutic targets of remyelination [27]. EAE is the most common use animal model of MS, which can be induced by myelin components, such as MOG, MBP, or PLP. In clinical, MS is categorized into four courses: (1) relapsing-remitting MS (RRMS), the most common form of MS which affect around $85 \%$ of MS patients; (2) secondary progressive MS (SPMS), developed followed by RRMS with time; (3) primary progressive MS (PPMS), around $15 \%$ patients with gradual progressive neurologic deterioration at the beginning of detectable clinical signs; and (4) progressive-relapsing MS (PRMS), the least common form of MS [96-98]. MS as a severe neurological disease leads to a wide range of symptoms to the patients. Hence, multiple drugs have been developed with the aim of promoting remyelination in MS patients in clinical settings, as described in Table 1. Although several pharmacologic manipulations of MS have been developed, a better understanding of neuroprotective effect of 


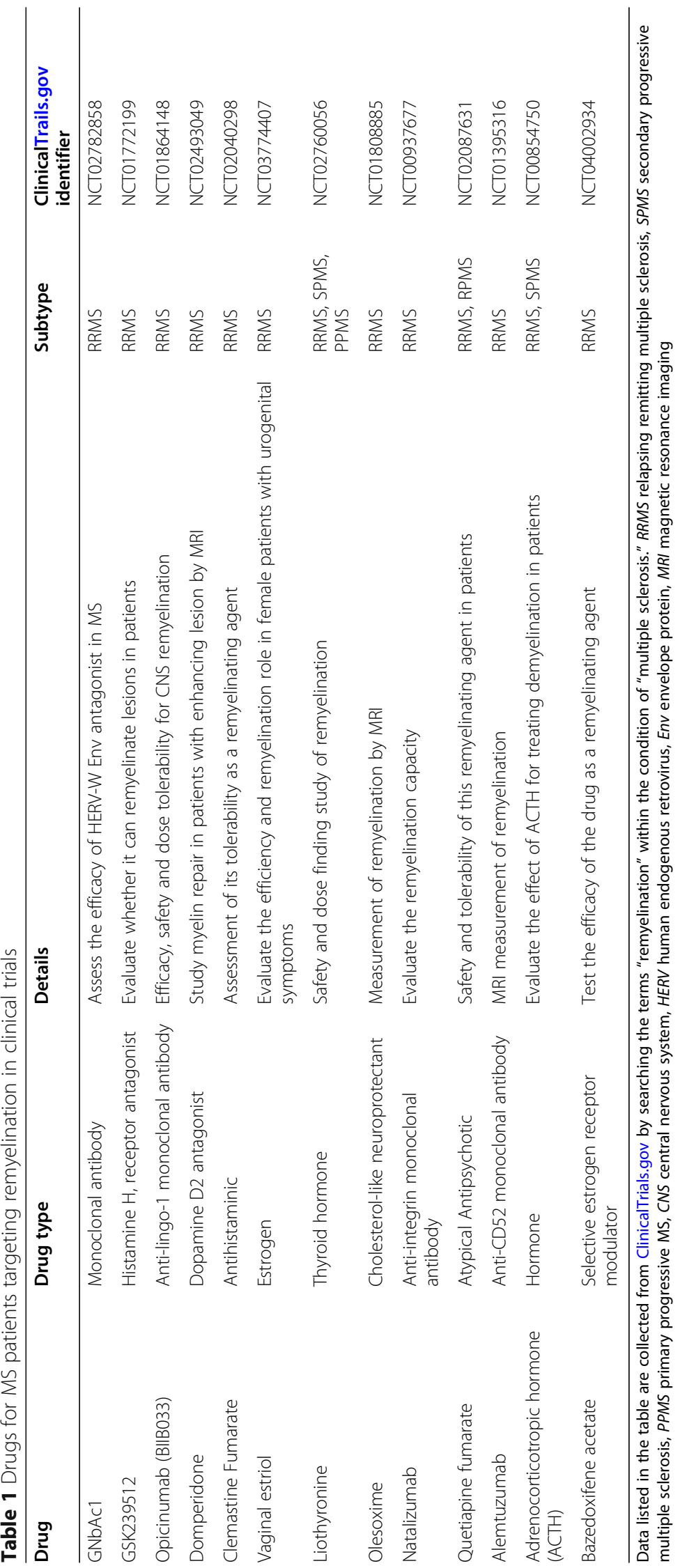


the available drugs and the development of drugs targeting new potential molecular targets will be needed to further contribute to the management of MS patients.

\section{Conclusion}

The long-lasting goal in regeneration toward CNS injury or diseases is to restore the lost function of nerve. To achieve this purpose, numerous cellular and molecular components are involved in the process. One approach is to replenish lost neural cells through the activation of neural stem cells (NSCs) and cell transplantation. The other approach is to manipulate the potential therapeutic target molecules of axon regeneration to achieve the functional recovery of CNS [99]. In the past decades, cell transplantation of stem cells, including ES and iPS cells appears to be an efficient therapeutic strategy for CNS injuries like SCI [100]. However, the therapeutic approach of cell transplantation contains several controversies, such as the unlimited NSCs proliferation that may lead to the tumor formation and the accuracy of cell differentiation for specific therapeutic effect [101]. Therefore, combination of cell transplantation and the knowledge of molecular mechanisms regulating cell development would be able to utilize cell transplantation therapy. Additionally, transplanted cells are also required to rebuild the neuronal network around the lesion; it is expected that the research underlying the molecular mechanisms of CNS regeneration will contribute to cell transplantation approach for treating CNS diseases. Nevertheless, successful regeneration and function restoration of CNS remain a great challenge. Although multiple potential targets have been investigated in recent studies, there is still a long journey for the development of efficient drugs for functional recovery of CNS. For this perspective, continued studies are needed to elucidate the detailed mechanism of CNS remyelination and the development of sufficient therapies for CNS injuries and diseases.

\footnotetext{
Abbreviations

CNS: Central nervous system; AD: Alzheimer's disease; MS: Multiple sclerosis; OPCs: Oligodendrocyte precursor cells; NG2: Neuron-glial antigen 2; OLs: Oligodendrocytes; PDGF: Platelet-derived growth factor; Myrf: Myelin regulatory factor; PDGFRa: Platelet-derived growth factor receptor a; MBP: Myelin basic protein; PLP: Proteolipid protein; MAG: Myelin-associated glycoprotein; MOG: Myelin oligodendrocyte glycoprotein; BBB: Blood-brain barrier; GFAP: Glial fibrillary acidic protein; TGF- $\beta$ : Tumor growth factor- $\beta$; BDNF: Brain-derived neurotrophic factor; LPC: Lysophosphatidylcholines; EAE: Experimental autoimmune encephalomyelitis; VEGF: Vascular endothelial growth factor; FGF: Fibroblast growth factor; IGF: Insulin-like growth factor 1; HGF: Hepatocyte growth factor; MMPs: Matrix metalloproteinases; LIF: Leukemia inhibitory factor; TIMP-1: Tissue inhibitor of metalloproteinases 1; CSPGs: Chondroitin sulphate proteoglycans; ET-1: Endothelin-1; IL: Interleukin; TNF: Tumor necrosis factor; CXCL: C-X-C motif chemokine ligand; DDAH1: Dimethylarginine dimethylaminohydrolase 1; APJ: Apelin receptor; BMP: Bone morphogenetic protein; SCl: Spinal cord injury; RRMS: Relapsingremitting MS; SPMS: Secondary progressive MS; PPMS: Primary progressive MS; PRMS: Progressive-relapsing MS; NSCs: Neural stem cells
}

Acknowledgments

Not applicable.

\section{Authors' contributions}

L.Q. wrote the manuscript. A.U. helped draft the manuscript. R.M. supervised the review. All authors read and approved the final manuscript.

\section{Funding}

This study was supported by the Japan Agency for Medical Research and Development (21gm6210020h) and Japan Society for the Promotion of Science (19H03554).

\section{Availability of data and materials \\ Not applicable.}

\section{Declarations}

Ethics approval and consent to participate

Not applicable.

\section{Consent for publication}

Not applicable.

\section{Competing interests}

The authors declare no competing interests.

Received: 26 August 2021 Accepted: 7 January 2022

Published online: 02 March 2022

\section{References}

1. Crawford AH, Chambers C, Franklin RJM. Remyelination: the true regeneration of the central nervous system. J Comp Pathol. 2013;149(2-3): 242-54. https://doi.org/10.1016/j.jcpa.2013.05.004.

2. Neumann B, Segel M, Chalut KJ, Franklin RJM. Remyelination and ageing: Reversing the ravages of time. Mult Scler J. 2019;25(14):1835-41. https://doi. org/10.1177/1352458519884006.

3. Baaklini CS, Rawji KS, Duncan GJ, Ho MFS, Plemel JR. Central nervous system remyelination: roles of glia and innate immune cells. Front Mol Neurosci. 2019;12:225. https://doi.org/10.3389/fnmol.2019.00225.

4. Bradl M, Lassmann H. Oligodendrocytes: biology and pathology. Acta Neuropathol. 2010;119(1):37-53. https://doi.org/10.1007/s00401-009-0601-5.

5. van Tilborg E, de Theije CGM, van Hal M, Wagenaar N, de Vries LS, Benders $\mathrm{MJ}$, et al. Origin and dynamics of oligodendrocytes in the developing brain: Implications for perinatal white matter injury. GLIA. 2018;66(2):221-38. https://doi.org/10.1002/glia.23256.

6. Dimou L, Simon C, Kirchhoff F, Takebayashi H, Götz M. Progeny of Olig2expressing progenitors in the gray and white matter of the adult mouse cerebral cortex. J Neurosci. 2008;28(41):10434-42. https://doi.org/10.1523/ JNEUROSCI.2831-08.2008.

7. Fancy SPJ, Zhao C, Franklin RJM. Increased expression of Nkx2.2 and Olig2 identifies reactive oligodendrocyte progenitor cells responding to demyelination in the adult CNS. Mol Cell Neurosci. 2004;27:247-54.

8. Hornig J, Fröb F, Vogl MR, Hermans-Borgmeyer I, Tamm ER, Wegner M. The transcription factors sox 10 and myrf define an essential regulatory network module in differentiating oligodendrocytes. PLoS Genet. 2013;9(10): e1003907. https://doi.org/10.1371/journal.pgen.1003907.

9. Weider M, Starost LJ, Groll K, Küspert M, Sock E, Wedel M, et al. Nfat/ calcineurin signaling promotes oligodendrocyte differentiation and myelination by transcription factor network tuning. Nat Commun. 2018;9(1): 1-16. https://doi.org/10.1038/s41467-018-03336-3.

10. Emery B, Lu QR. Transcriptional and epigenetic regulation of oligodendrocyte development and myelination in the central nervous system. Cold Spring Harb Perspect Biol. 2015;7(9). https://doi.org/10.1101/ cshperspect.a020461.

11. Zhao C, Ma D, Zawadzka M, Fancy SPJ, Elis-Williams L, Bouvier G, et al. Sox2 sustains recruitment of oligodendrocyte progenitor cells following CNS demyelination and primes them for differentiation during remyelination. J Neurosci. 2015;35(33):11482-99. https://doi.org/10.1523/JNEUROSCl.3 655-14.2015.

12. Huang $H$, Teng $P, D u J$, Meng J, Hu X, Tang T, et al. Interactive repression of MYRF self-cleavage and activity in oligodendrocyte differentiation by 
TMEM98 protein. J Neurosci. 2018;38(46):9829-39. https://doi.org/10.1523/ JNEUROSCI.0154-18.2018.

13. Fancy SPJ, Baranzini SE, Zhao C, Yuk DI, Irvine KA, Kaing S, et al. Dysregulation of the Wnt pathway inhibits timely myelination and remyelination in the mammalian CNS. Genes Dev. 2009;23(13):1571-85. https://doi.org/10.1101/gad.1806309.

14. Weng C, Ding M, Fan S, Cao Q, Lu Z. Transcription factor 7 like 2 promotes oligodendrocyte differentiation and remyelination. Mol Med Rep. 2017;16(2): 1864-70. https://doi.org/10.3892/mmr.2017.6843.

15. Chew LJ, Ming X, McEllin B, Dupree J, Hong E, Catron M, et al. Sox17 regulates a program of oligodendrocyte progenitor cell expansion and differentiation during development and repair. Cell Rep. 2019;29:3173-3186. e7. https://doi.org/10.1016/j.celrep.2019.10.121.

16. Zhou B, Zhu Z, Ransom BR, Tong X. Oligodendrocyte lineage cells and depression. Molecular Psychiatry. 2021;26(1):103-17. https://doi.org/10.1038/ s41380-020-00930-0.

17. Spitzer SO, Sitnikov S, Kamen Y, Evans KA, Kronenberg-Versteeg D, Dietmann $\mathrm{S}$, et al. Oligodendrocyte progenitor cells become regionally diverse and heterogeneous with age. Neuron. 2019;101:459-471.e5. https:// doi.org/10.1016/j.neuron.2018.12.020.

18. Neumann B, Baror R, Zhao C, Segel M, Dietmann S, Rawji KS, et al. Metformin restores CNS remyelination capacity by rejuvenating aged stem cells. Cell Stem Cell. 2019;25:473-485.e8. https://doi.org/10.1016/j.stem.2019. 08.015 .

19. Cantuti-Castelvetri L, Fitzner D, Bosch-Queralt M, Weil M-T, Su M, Sen P, et al. Defective cholesterol clearance limits remyelination in the aged central nervous system. Science. 2018;359(6376):684-8. https://doi.org/1 $0.1126 /$ science.aan4183.

20. Jäkel S, Agirre E, Mendanha Falcão A, van Bruggen D, Lee KW, Knuesel I, et al. Altered human oligodendrocyte heterogeneity in multiple sclerosis. Nature. 2019;566(7745):543-7. https://doi.org/10.1038/s41586-019-0903-2.

21. Crawford AH, Tripathi RB, Foerster S, McKenzie I, Kougioumtzidou E, Grist M, et al. Pre-existing mature oligodendrocytes do not contribute to remyelination following toxin-induced spinal cord demyelination. Am J Pathol. 2016;186(3):511-6. https://doi.org/10.1016/j.ajpath.2015.11.005.

22. Duncan ID, Radcliff AB, Heidari M, Kidd G, August BK, Wierenga LA. The adult oligodendrocyte can participate in remyelination. Proc Natl Acad Sci. 2018;115(50):E11807-16. https://doi.org/10.1073/pnas.1808064115.

23. Yeung MSY, Djelloul M, Steiner E, Bernard S, Salehpour M, Possnert G, et al. Dynamics of oligodendrocyte generation in multiple sclerosis. Nature. 2019; 566(7745):538-42. https://doi.org/10.1038/s41586-018-0842-3.

24. Factor DC, Barbeau AM, Allan KC, Hu LR, Madhavan M, Hoang AT, et al. Cell type-specific intralocus interactions reveal oligodendrocyte mechanisms in MS. Cell. 2020;181:382-395.e21. https://doi.org/10.1016/j.cell.2020.03.002.

25. Tkachev D, Mimmack ML, Ryan MM, Wayland M, Freeman T, Jones PB, et al. Oligodendrocyte dysfunction in schizophrenia and bipolar disorder. Lancet. 2003:362(9386):798-805. https://doi.org/10.1016/S0140-6736(03)14289-4.

26. Zhang P, Kishimoto Y, Grammatikakis I, Gottimukkala K, Cutler RG, Zhang $S$, et al. Senolytic therapy alleviates A $\beta$-associated oligodendrocyte progenitor cell senescence and cognitive deficits in an Alzheimer's disease model. Nat Neurosci. 2019;22(5):719-28. https://doi. org/10.1038/s41593-019-0372-9.

27. Uyeda A, Muramatsu R. Molecular mechanisms of central nervous system axonal regeneration and remyelination: a review. Int J Mol Sci. 2020;21(21): 8116. https://doi.org/10.3390/ijms21218116.

28. Petersen MA, Ryu JK, Chang K-J, Etxeberria A, Bardehle S, Mendiola AS, et al. Fibrinogen activates BMP signaling in oligodendrocyte progenitor cells and inhibits remyelination after vascular damage. Neuron. 2017;96:1003-1012.e7. https://doi.org/10.1016/..neuron.2017.10.008.

29. Kuroda M, Muramatsu R, Maedera N, Koyama Y, Hamaguchi M, Fujimura H, et al. Peripherally derived FGF21 promotes remyelination in the central nervous system. J Clin Invest. 2017;127(9):3496-509. https://doi.org/10.1172/ JC194337.

30. Hamaguchi M, Muramatsu R, Fujimura H, Mochizuki H, Kataoka H, Yamashita T. Circulating transforming growth factor- $\beta 1$ facilitates remyelination in the adult central nervous system. Elife. 2019;8:1-20. https://doi.org/10.7554/ elife.41869.

31. Ito M, Muramatsu R, Kato Y, Sharma B, Uyeda A, Tanabe S, et al. Agedependent decline in remyelination capacity is mediated by apelin-APJ signaling. Nat Aging. 2021;1(3):284-94. https://doi.org/10.1038/s43587-02100041-7.
32. Tennent GA, Brennan SO, Stangou AJ, O'Grady J, Hawkins PN, Pepys MB. Human plasma fibrinogen is synthesized in the liver. Blood. 2007:109(5): 1971-4. https://doi.org/10.1182/blood-2006-08-040956.

33. Schachtrup C, Ryu JK, Helmrick MJ, Vagena E, Galanakis DK, Degen JL, et al. Fibrinogen triggers astrocyte scar formation by promoting the availability of active TGF- $\beta$ after vascular damage. J Neurosci. 2010;30(17):5843-54. https:// doi.org/10.1523/JNEUROSCI.0137-10.2010.

34. Pous L, Deshpande SS, Nath S, Mezey S, Malik SC, Schildge S, et al. Fibrinogen induces neural stem cell differentiation into astrocytes in the subventricular zone via BMP signaling. Nat Commun. 2020;11(1):1-13. https://doi.org/10.1038/s41467-020-14466-y.

35. Nakasone A, Muramatsu R, Kato Y, Kawahara Y, Yamashita T. Myotubederived factor promotes oligodendrocyte precursor cell proliferation. Biochem Biophys Res Commun. 2018;500(3):609-13. https://doi.org/10.1016/ j.bbrc.2018.04.118.

36. Kuroda M, Muramatsu R, Yamashita T. Cardiomyocyte-released factors stimulate oligodendrocyte precursor cells proliferation. Biochem Biophys Res Commun. 2017;482(4):1160-4. https://doi.org/10.1016/j.bbrc.2016.12.004.

37. Matoba K, Muramatsu R, Yamashita T. Leptin sustains spontaneous remyelination in the adult central nervous system. Sci Rep. 2017;7(1):40397. https://doi.org/10.1038/srep40397.

38. Pluvinage JV, Wyss-Coray T. Systemic factors as mediators of brain homeostasis, ageing and neurodegeneration. Nat Rev Neurosci. 2020;21(2): 93-102. https://doi.org/10.1038/s41583-019-0255-9.

39. Abbott NJ, Rönnbäck L, Hansson E. Astrocyte-endothelial interactions at the blood-brain barrier. Nature Reviews Neuroscience. 2006;7(1):41-53. https:// doi.org/10.1038/nrn1824.

40. Macvicar BA, Newman EA. Astrocyte regulation of blood flow in the brain. Cold Spring Harb Perspect Biol. 2015;7(5):1-15. https://doi.org/10.1101/ cshperspect.a020388.

41. Ben Haim L, Rowitch DH. Functional diversity of astrocytes in neural circuit regulation. Nature Reviews Neuroscience. 2016;18(1):31-41. https://doi.org/1 0.1038/nrn.2016.159.

42. Hamilton NB, Attwell D. Do astrocytes really exocytose neurotransmitters? Nature Reviews Neuroscience. 2010;11(4):227-38. https://doi.org/10.1038/ nrn2803.

43. Sofroniew MV. Astrocyte reactivity: subtypes, states, and functions in CNS innate immunity. Trends in Immunology. 2020;41(9):758-70. https://doi. org/10.1016/j.it.2020.07.004.

44. Christopherson KS, Ullian EM, Stokes CCA, Mullowney CE, Hell JW, Agah A, et al. Thrombospondins are astrocyte-secreted proteins that promote CNS synaptogenesis. Cell. 2005;120(3):421-33. https://doi.org/10.1016/j.cell.2 004.12.020.

45. Allen NJ, Bennett ML, Foo LC, Wang GX, Chakraborty C, Smith SJ, et al. Astrocyte glypicans 4 and 6 promote formation of excitatory synapses via GluA1 AMPA receptors. Nature. 2012;486(7403):410-4. https://doi.org/10.103 8/nature11059.

46. Giovannoni F, Quintana FJ. The role of astrocytes in CNS inflammation. Trends Immunol. 2020;41(9):805-19. https://doi.org/10.1016/j.it.2020.07.007.

47. Escartin C, Galea E, Lakatos A, O'Callaghan JP, Petzold GC, Serrano-Pozo A, et al. Reactive astrocyte nomenclature, definitions, and future directions. Nat Neurosci. 2021;24(3):312-25. https://doi.org/10.1038/s41593-020-00783-4.

48. Zamanian JL, Xu L, Foo LC, Nouri N, Zhou L, Giffard RG, et al. Genomic analysis of reactive astrogliosis. J Neurosci. 2012;32(18):6391-410. https://doi. org/10.1523/JNEUROSCI.6221-11.2012.

49. Liddelow SA, Guttenplan KA, Clarke LE, Bennett FC, Bohlen CJ, Schirmer L, et al. Neurotoxic reactive astrocytes are induced by activated microglia. Nature. 2017;541 (7638):481-7. https://doi.org/10.1038/nature21029.

50. Yun SP, Kam Tl, Panicker N, Kim S, Oh Y, Park JS, et al. Block of A1 astrocyte conversion by microglia is neuroprotective in models of Parkinson's disease. Nat Med. 2018;24(7):931-8. https://doi.org/10.1038/s41591-018-0051-5.

51. Habib N, McCabe C, Medina S, Varshavsky M, Kitsberg D, Dvir-Szternfeld R, et al. Disease-associated astrocytes in Alzheimer's disease and aging. Nat Neurosci. 2020;23(6):701-6. https://doi.org/10.1038/s41593-020-0624-8.

52. Diaz-Castro B, Gangwani MR, Yu X, Coppola G, Khakh BS. Astrocyte molecular signatures in Huntington's disease. Sci Transl Med. 2019;11(514): 1-13. https://doi.org/10.1126/scitranslmed.aaw8546.

53. Al-Dalahmah O, Sosunov AA, Shaik A, Ofori K, Liu Y, Vonsattel JP, et al. Single-nucleus RNA-seq identifies Huntington disease astrocyte states. Acta Neuropathol Commun. 2020;8(1):1-21. https://doi.org/10.1186/s40478-0200880-6. 
54. Sun S, Sun Y, Ling SC, Ferraiuolo L, McAlonis-Downes M, Zou Y, et al. Translational profiling identifies a cascade of damage initiated in motor neurons and spreading to glia in mutant sod1-mediated ALS. Proc Natl Acad Sci U S A. 2015;112(50):E6993-7002. https://doi.org/10.1073/pnas.152 0639112.

55. Batiuk MY, Martirosyan A, Wahis J, de Vin F, Marneffe C, Kusserow C, et al. Identification of region-specific astrocyte subtypes at single cell resolution. Nat Commun. 2020;11(1):1220. https://doi.org/10.1038/s41467-019-14198-8.

56. Itoh N, Itoh Y, Tassoni A, Ren E, Kaito M, Ohno A, et al. Cell-specific and region-specific transcriptomics in the multiple sclerosis model: Focus on astrocytes. Proc Natl Acad Sci. 2018;115(2):E302-9. https://doi.org/10.1073/ pnas.1716032115.

57. Rawji KS, Gonzalez Martinez GA, Sharma A, Franklin RJM. The role of astrocytes in remyelination. Trends Neurosci. 2020;43(8):596-607. https://doi. org/10.1016/j.tins.2020.05.006.

58. Hinks GL, Franklin RJM. Distinctive patterns of PDGF-A, FGF-2, IGF-I, and TGF- $\beta 1$ gene expression during remyelination of experimentally-induced spinal cord demyelination. Mol Cell Neurosci. 1999;14(2):153-68. https://doi. org/10.1006/mcne.1999.0771

59. Messersmith DJ, Murtie JC, Le TQ, Frost EE, Armstrong RC. Fibroblast growth factor 2 (FGF2) and FGF receptor expression in an experimental demyelinating disease with extensive remyelination. J Neurosci Res. 2000; 62(2):241-56. https://doi.org/10.1002/1097-4547(20001015)62:2<241::AIDJNR9>3.0.CO;2-D.

60. Fischer R, Wajant H, Kontermann R, Pfizenmaier K, Maier O. Astrocytespecific activation of TNFR2 promotes oligodendrocyte maturation by secretion of leukemia inhibitory factor. Glia. 2014;62(2):272-83. https://doi. org/10.1002/glia.22605.

61. Tsai H-H, Frost E, To V, Robinson S, Ffrench-Constant C, Geertman R, et al. The chemokine feceptor CXCR2 controls oositioning of oligodendrocyte precursors in developing spinal cord by arresting their migration. Cell. 2002; 110(3):373-83. https://doi.org/10.1016/S0092-8674(02)00838-3.

62. Omari KM, John GR, Sealfon SC, Raine CS. CXC chemokine receptors on human oligodendrocytes: Implications for multiple sclerosis. Brain. 2005; 128(5):1003-15. https://doi.org/10.1093/brain/awh479.

63. Stankoff B, Aigrot MS, Noël F, Wattilliaux A, Zalc B, Lubetzki C. Ciliary neurotrophic factor (CNTF) enhances myelin formation: a novel role for CNTF and CNTF-related molecules. J Neurosci. 2002;22(21):9221-7. https:// doi.org/10.1523/jneurosci.22-21-09221.2002.

64. Deverman BE, Patterson PH. Exogenous leukemia inhibitory factor stimulates oligodendrocyte progenitor cell proliferation and enhances hippocampal remyelination. J Neurosci. 2012;32(6):2100-9. https://doi.org/1 0.1523/JNEUROSCI.3803-11.2012.

65. McMorris FA, Smith TM, DeSalvo S, Furlanetto RW. Insulin-like growth factor I/somatomedin C: a potent inducer of oligodendrocyte development. Proc Natl Acad Sci. 1986;83(3):822-6. https://doi.org/10.1073/pnas.83.3.822.

66. Houben E, Janssens K, Hermans D, Vandooren J, van den Haute C, Schepers $M$, et al. Oncostatin M-induced astrocytic tissue inhibitor of metalloproteinases-1 drives remyelination. Proc Natl Acad Sci U S A. 2020; 117(9):5028-38. https://doi.org/10.1073/pnas.1912910117.

67. Keough MB, Rogers JA, Zhang P, Jensen SK, Stephenson EL, Chen T, et al. An inhibitor of chondroitin sulfate proteoglycan synthesis promotes central nervous system remyelination. Nat Commun. 2016;7(1). https://doi.org/10.1 038/ncomms 11312 .

68. Hammond TR, Gadea A, Dupree J, Kerninon C, Nait-Oumesmar B, Aguirre A, et al. Astrocyte-derived endothelin-1 inhibits remyelination through notch activation. Neuron. 2014;81(6):1442. https://doi.org/10.1016/j.neuron.2014.03. 007.

69. Stoffels JMJ, De Jonge JC, Stancic M, Nomden A, Van Strien ME, Ma D, et al. Fibronectin aggregation in multiple sclerosis lesions impairs remyelination. Brain. 2013;136(1):116-31. https://doi.org/10.1093/brain/aws313.

70. Czopka T, Von Holst A, Ffrench-Constant C, Faissner A. Regulatory mechanisms that mediate tenascin C-dependent inhibition of oligodendrocyte precursor differentiation. J Neurosci. 2010;30(37):12310-22. https://doi.org/10.1523/JNEUROSCI.4957-09.2010.

71. Hammond TR, McEllin B, Morton PD, Raymond M, Dupree J, Gallo V. Endothelin-B receptor activation in astrocytes regulates the rate of oligodendrocyte regeneration during remyelination. Cell Rep. 2015;13(10): 2090-7. https://doi.org/10.1016/j.celrep.2015.11.002.

72. Miyamoto N, Maki T, Shindo A, Liang AC, Maeda M, Egawa N, et al. Astrocytes promote oligodendrogenesis after white matter damage via brain-derived neurotrophic factor. J Neurosci. 2015;35(41):14002-8. https:// doi.org/10.1523/JNEUROSCI.1592-15.2015.

73. Back SA, Tuohy TMF, Chen H, Wallingford N, Craig A, Struve J, et al. Hyaluronan accumulates in demyelinated lesions and inhibits oligodendrocyte progenitor maturation. Nat Med. 2005;11(9):966-72. https:// doi.org/10.1038/nm1279.

74. Lindner M, Thümmler K, Arthur A, Brunner S, Elliott C, McElroy D, et al. Fibroblast growth factor signalling in multiple sclerosis: inhibition of myelination and induction of pro-inflammatory environment by FGF9. Brain. 2015:138(7):1875-93. https://doi.org/10.1093/brain/awv102.

75. Colombo E, Triolo D, Bassani C, Bedogni F, Di Dario MD, Dina G, et al. Dysregulated copper transport in multiple sclerosis may cause demyelination via astrocytes. Proc Natl Acad Sci U S A. 2021;118(27): e2025804118. https://doi.org/10.1073/pnas.2025804118.

76. Skripuletz T, Hackstette D, Bauer K, Gudi V, Pul R, Voss E, et al. Astrocytes regulate myelin clearance through recruitment of microglia during cuprizone-induced demyelination. Brain. 2013;136(1):147-67. https://doi. org/10.1093/brain/aws262.

77. Berghoff SA, Gerndt N, Winchenbach J, Stumpf SK, Hosang L, Odoardi F, et al. Dietary cholesterol promotes repair of demyelinated lesions in the adult brain. Nat Commun. 2017:8(1):1-15. https://doi.org/10.1038/ ncomms14241.

78. Zhang J, Liu Q. Cholesterol metabolism and homeostasis in the brain. Protein Cell. 2015;6(4):254-64. https://doi.org/10.1007/s13238-014-0131-3.

79. Wright-Jin EC, Gutmann DH. Microglia as dynamic cellular mediators of brain function. Trends Mol Med. 2019;25(11):967-79. https://doi.org/10.1016/ j.molmed.2019.08.013.

80. Kyritsis N, Kizil C, Brand M. Neuroinflammation and central nervous system regeneration in vertebrates. Trends in Cell Biology. 2014;24(2):128-35. https://doi.org/10.1016/j.tcb.2013.08.004.

81. Lloyd AF, Davies CL, Holloway RK, Labrak Y, Ireland G, Carradori D, et al. Central nervous system regeneration is driven by microglia necroptosis and repopulation. Nat Neurosci. 2019;22(7):1046-52. https://doi.org/10.1038/s41 593-019-0418-z.

82. Bachiller S, Jiménez-Ferrer I, Paulus A, Yang Y, Swanberg M, Deierborg T, et al. Microglia in neurological diseases: a road map to brain-disease dependent inflammatory response. Front Cell Neurosci. 2018;12. https://doi. org/10.3389/fncel.2018.00488.

83. Nathan C, Calingasan N, Nezezon J, Ding A, Lucia MS, La Perle K, et al. Protection from Alzheimer's-like disease in the mouse by genetic ablation of inducible nitric oxide synthase. J Exp Med. 2005;202(9):1163-9. https:// doi.org/10.1084/jem.20051529.

84. Tang $Y$, Le W. Differential Roles of M1 and M2 microglia in neurodegenerative diseases. Molecular Neurobiology. 2016:53(2):1181-94. https://doi.org/10.1007/s12035-014-9070-5.

85. Kobashi S, Terashima T, Katagi M, Nakae Y, Okano J, Suzuki Y, et al. Transplantation of M2-deviated microglia promotes recovery of motor function after spinal cord injury in mice. Mol Ther. 2020;28(1):254-65. https://doi.org/10.1016/j.ymthe.2019.09.004.

86. Miron VE, Boyd A, Zhao JW, Yuen TJ, Ruckh JM, Shadrach JL, et al. M2 microglia and macrophages drive oligodendrocyte differentiation during CNS remyelination. Nat Neurosci. 2013;16(9):1211-8. https://doi.org/10.1038/ nn.3469.

87. Lloyd AF, Miron VE. The pro-remyelination properties of microglia in the central nervous system. Nat Rev Neurol. 2019;15(8):447-58. https://doi.org/1 0.1038/s41582-019-0184-2.

88. Lampron A, Larochelle A, Laflamme N, Préfontaine P, Plante MM, Sánchez $M G$, et al. Inefficient clearance of myelin debris by microglia impairs remyelinating processes. J Exp Med. 2015;212(4):481-95. https://doi.org/10.1 084/jem.20141656.

89. Natrajan MS, De La Fuente AG, Crawford AH, Linehan E, Nuñez V, Johnson $\mathrm{KR}$, et al. Retinoid $\mathrm{X}$ receptor activation reverses age-related deficiencies in myelin debris phagocytosis and remyelination. Brain. 2015;138(12):3581-97. https://doi.org/10.1093/brain/awv289.

90. Miron VE. Microglia-driven regulation of oligodendrocyte lineage cells, myelination, and remyelination. J Leukoc Biol. 2017;101(5):1103-8. https:// doi.org/10.1189/jlb.3ri1116-494r.

91. Sariol A, Mackin S, Allred MG, Ma C, Zhou Y, Zhang Q, et al. Microglia depletion exacerbates demyelination and impairs remyelination in a neurotropic coronavirus infection. Proc Natl Acad Sci U S A. 2020;117(39): 24464-74. https://doi.org/10.1073/pnas.2007814117. 
92. Zhang Q, Zhu W, Xu F, Dai X, Shi L, Cai W, et al. The interleukin-4/PPARY signaling axis promotes oligodendrocyte differentiation and remyelination after brain injury. PLoS Biol. 2019;17(6):e3000330. https://doi.org/10.1371/ journal.pbio.3000330.

93. Filippi M, Bar-Or A, Piehl F, Preziosa P, Solari A, Vukusic S, et al. Multiple sclerosis. Nat Rev Dis Prim. 2018;4(1):1-27. https://doi.org/10.1038/s41572-01 8-0041-4.

94. Florou D, Katsara M, Feehan J, Dardiotis E, Apostolopoulos V. Anti-cd20 agents for multiple sclerosis: spotlight on ocrelizumab and ofatumumab. Brain Sciences. 2020;10(10):1-13. https://doi.org/10.3390/brainsci10100758.

95. Lubetzki C, Zalc B, Williams A, Stadelmann C, Stankoff B. Remyelination in multiple sclerosis: from basic science to clinical translation. Lancet Neurol. 2020;19(8):678-88. https://doi.org/10.1016/S1474-4422(20)30140-X.

96. Dargahi N, Katsara M, Tselios T, Androutsou M-E, de Courten M, Matsoukas J, et al. Multiple Sclerosis: immunopathology and Treatment Update. Brain Sci. 2017;7(12):78. https://doi.org/10.3390/brainsci7070078.

97. Coetzee T, Thompson AJ. Unified understanding of MS course is required for drug development. Nature Reviews Neurology. 2018;14(4):191-2. https:// doi.org/10.1038/nrneurol.2017.184.

98. Meca-Lallana V, Berenguer-Ruiz L, Carreres-Polo J, Eichau-Madueño S, FerrerLozano J, Forero L, et al. Deciphering Multiple Sclerosis Progression. Front Neurol. 2021;12:477. https://doi.org/10.3389/fneur.2021.608491.

99. Okano H. Strategic approaches to regeneration of a damaged central nervous system. In: Cornea. 2011;30 Suppl 1:S15-8. https://doi.org/10.1097/ ICO.0b013e3182281879.

100. Nagoshi N, Okano H, Nakamura M. Regenerative therapy for spinal cord injury using iPSC technology. Inflammation and Regeneration. 2020;40(1):15. https://doi.org/10.1186/s41232-020-00149-0.

101. Zakrzewski W, Dobrzyński M, Szymonowicz M, Rybak Z. Stem cells: past, present, and future. Stem Cell Research and Therapy. 2019;10(1):1-22. https://doi.org/10.1186/s13287-019-1165-5.

\section{Publisher's Note}

Springer Nature remains neutral with regard to jurisdictional claims in published maps and institutional affiliations.

Ready to submit your research? Choose BMC and benefit from:

- fast, convenient online submission

- thorough peer review by experienced researchers in your field

- rapid publication on acceptance

- support for research data, including large and complex data types

- gold Open Access which fosters wider collaboration and increased citations

- maximum visibility for your research: over $100 \mathrm{M}$ website views per year

At $\mathrm{BMC}$, research is always in progress.

Learn more biomedcentral.com/submissions 